\title{
Impact of Saccharomyces cerevisiae supplementation on reproductive performance, milk yield in ewes and offspring growth
}

\author{
B. Zaleska, S. Milewski, and K. Ząbek \\ Department of Sheep and Goat Breeding, Faculty of Animal Bioengineering, University of Warmia and Mazury \\ in Olsztyn, Olsztyn, Poland \\ Correspondence to: K. Ząbek (katarzyna.zabek@uwm.edu.pl)
}

Received: 15 September 2014 - Accepted: 27 January 2015 - Published: 6 March 2015

\begin{abstract}
The effect of supplementing sheep diets with Saccharomyces cerevisiae Inter Yeast ${ }^{\circledR}$ dried brewer's yeast (Leiber GmbH, Bramsche, Germany) or with a Biolex ${ }^{\circledR}$ Beta-S (Leiber GmbH, Bramsche, Germany) extract containing over $70 \% \beta$-1,3/1,6-D-glucan was investigated. Experiment 1 was carried out with 120 ewes and 190 lambs. The animals were divided into three groups: I - control; II - fed yeast; and III - fed Biolex. The supplements were administered during a 3-week preparation period for tupping and a 70-day lamb-rearing period. The following reproductive parameters were analysed: fertility, prolificacy, lamb rearing and breeding performance, milk yield and lamb growth rate. Experiment 2 was conducted with 120 ewes divided into two groups: I - control and II - fed yeast during a 3-week preparation period. Fertility and prolificacy were analysed. Significant increases in prolificacy were recorded in sheep administered dried brewer's yeast: $28.51 \%$ in experiment 1 and $31.33 \%$ in experiment 2 . Breeding performance was also higher by $35 \%$. Both yeast supplements had a stimulating impact on the milk yield of ewes and the growth rate of their offspring. Milk from the experimental ewes, especially in the group fed Biolex, had a substantially higher content of dry matter, mainly fat. The lambs in this group had the highest body weight at the age of 70 days. Finally, however, the production of livestock per mother was highest in the group fed the supplement with Saccharomyces cerevisiae.
\end{abstract}

\section{Introduction}

Currently, there is a trend towards obtaining animal-derived food products with high health-promoting properties. This is associated with an increased proportion of natural feedstuffs in animal diets, yet it is known that such types of feed may reduce productivity. Therefore, current research is focused on ways to stimulate animal productivity by, for instance, introducing natural feed supplements which are compliant with general animal welfare. Increasingly often, preparations containing microorganisms or their products are being used. Of these, supplements derived from Saccharomyces cerevisiae yeasts have attracted special attention because they are characterized by high activity thanks to the mannans and glucose polymers found in their cell walls. They show a wide spectrum of activity in the body which, in turn, results in an increase in health status and the level of production. The prop- erties of Saccharomyces cerevisiae offer the potential for use as a natural stimulator in animal nutrition. In a sense, yeasts may replace antibiotic growth stimulators which were withdrawn in 2006, although views on this matter are divided (Erasmus et al., 2005; Linge, 2005). Most studies on the effect of Saccharomyces cerevisiae dried brewer's yeast in animal nutrition have been carried out on cattle. It has been shown that the addition of brewer's yeasts in a dairy cow diet caused an increase in milk yield and a reduction of somatic cell count in milk (Dobicki et al., 2006, 2007). Studies by Dobicki et al. (2005) demonstrated that an addition of Saccharomyces cerevisiae reduced the consumption of concentrates per kilogram of weight gain and affected the structure of microbiota in the ruminal fluid in calves. An increase in milk yield associated with the supplementation of the diet with yeast products has been also shown in sheep (Milewski and Sobiech, 2009; Ząbek et al., 2014). $\beta$-1,3/1,6-D-glucan 
obtained from Saccharomyces cerevisiae is categorized as a natural immunostimulator, and its high level of activity in sheep has been demonstrated in studies (e.g. Milewski et al., 2007, and Wójcik et al., 2007). These effects were combined with a beneficial impact on meat (Milewski, 2009; Milewski et al., 2007) and milk (Ząbek et al., 2013) performance.

The range of studies on the effects of such supplements on performance traits in sheep is still relatively limited and, hence, the objective of the conducted studies was to determine the impact of Saccharomyces cerevisiae dried brewer's yeast and separated $\beta-1,3 / 1,6-\mathrm{D}$-glucan on the reproductive parameters, milk yield and chemical composition as well as the lamb growth rate. Since yeast supplements display an immunostimulating activity, it is assumed that they have a beneficial effect on performance parameters in sheep.

\section{Material and methods}

\subsection{Structure of the studies}

Two studies were conducted on the effects of Saccharomyces cerevisiae Inter Yeast ${ }^{\circledR}$ dried brewer's yeast and an extract thereof, Biolex ${ }^{\circledR}$ Beta-S, containing over $70 \% \beta$-1,3/1,6-Dglucan used in sheep nutrition. These supplements were administered with a concentrate in the following proportions: $50 \mathrm{~g}$ of yeast per kilogram of feed and $3 \mathrm{~g}$ of Biolex per kilogram of feed.

\subsubsection{Experiment 1}

This experiment was carried out in a Polish Longwool sheep breeding herd with 120 ewes aged 3-5 years and 190 lambs. Before the experiment, the ewes were divided into three groups (analogous in age and body weight) of 40 individuals each: I - control, and II and III - experimental. The nutrition level was identical in all groups. The experimental ewes were administered supplements during a 3-week preparation period for tupping and during a 70-day lactation and lamb rearing period: yeasts for group II and Biolex for group III. During the preparation period for tupping, the ewes were on a pasture and their diet was supplemented with a $\mathrm{CJ}^{\circledR}$ mix. During lactation, a composition of feeds was used: meadow hay, lucerne silage and a CJ mix. The doses of CJ mix were fixed: $0.3 \mathrm{~kg}$ per animal per day during the preparation period for tupping and $0.7 \mathrm{~kg}$ per animal per day during lactation. Components of the mixture (CJ) was as follows: ground barley $(40 \%)$, ground wheat $(37.5 \%)$, ground maize $(10 \%)$, soybean meal $(10 \%)$, mineral premix $(2 \%)$, fodder chalk $(0.2 \%)$, dicalcium phosphate $(0.2 \%)$ and salt fodder $(0.10 \%)$. The lambs in all groups were fed at an identical level using the same composition of feed as their mothers. Apart from their mothers' milk, the lambs were fed meadow hay and a CJ mix between day 11 and 30 and the diet was then supplemented with lucerne silage. The doses of CJ mix increased every 10 days by $0.05 \mathrm{~kg}$, starting from $0.05 \mathrm{~kg}$ per animal per day at the age of 11-20 days.

\subsubsection{Experiment 2}

This experiment was conducted in a Polish Lowland sheep breeding herd with 200 ewes aged 3-5 years divided into two groups (analogous in age and body weight) of 100 individuals each: I - control and II - experimental. The experimental ewes were administered yeast for a 3-week preparation period for tupping. The pasture, which provided the majority of nutrition, was supplemented with oat grain. In both herds, tupping lasted 6 weeks from mid-July until the end of August.

All procedures related to the animals in this study were approved by the Local Ethical Committee for Animal Experiments in Olsztyn (31/2009).

\subsubsection{Analysed parameters}

The efficiency of breeding performance was analysed in both studies while the milk yield of the ewes and the growth rates of the lambs were evaluated in experiment 1 .

The following criteria were applied to assess breeding performance: fertility - the ratio of the number of lambed ewes to the number of ewes selected for breeding; prolificacy - the ratio of the number of born lambs to the number of lambed ewes; rearing of lambs - the ratio of reared lambs to the number of live-born lambs; reproductive performance - the ratio of the number of reared lambs to the number of ewes selected for breeding. In experiment 2 , only fertility and prolificacy were determined.

Milk yield in the ewes was recorded on day 28 and 70 of lactation. To this end, eight mothers nurturing single lambs were randomly selected in each group. Daily milk production was determined based on a morning control milking that was performed after a $12 \mathrm{~h}$ break in lamb nurturing. $5 \mathrm{IU}$ of oxytocin were injected intramuscularly 2 min before milking (Niżnikowski and Rant, 1997) in order to stimulate constriction of the milk alveoli and lactiferous ducts in the mammary gland. Milk was collected manually from the right half of the udder while the left half was simultaneously suckled by a lamb. The volume of collected milk was multiplied by 4 to obtain daily production. For the milk, the percentage content of dry matter, fat, protein and lactose was then determined using a Combi Foss 6000 apparatus (Foss GmbH, Rellingen, Germany).

The evaluation of the growth rate in lambs included the body weight at the ages of 2, 28 and 70 days, and daily weight gains and growth rate parameters for the periods of days $2-28,29-70$ and $2-70$. The lamb growth rate (GR) was determined with the following formula (Milewski et al., 2010):

$\mathrm{GR}=\frac{\text { final body weight }- \text { initial body weight }}{1 / 2 \text { (initial body weight }+ \text { final body weight })} \times 100(\%)$. 
Table 1. Results of the breeding performance of the ewes.

\begin{tabular}{llll}
\hline \multirow{2}{*}{ Specification } & \multicolumn{3}{c}{ Group } \\
\cline { 2 - 4 } & I & II & III \\
\hline Experiment 1 & & & \\
\hline Fertility & 90.00 & 95.00 & 97.50 \\
Prolificacy & $158.33^{\mathrm{b}}$ & $186.84^{\mathrm{a}}$ & $156.41^{\mathrm{b}}$ \\
Rearing of lambs & 94.74 & 97.14 & 94.91 \\
Reproductive performance & $135.00^{\mathrm{b}}$ & $170.00^{\mathrm{a}}$ & $140.00^{\mathrm{b}}$ \\
\hline Experiment 2 & & & \\
\hline Fertility & 100.00 & 100.00 & - \\
Prolificacy & $126.67^{\mathrm{b}}$ & $158.33^{\mathrm{a}}$ & - \\
\hline
\end{tabular}

${ }^{\mathrm{a}, \mathrm{b}} p \leq 0.01$

The results were statistically processed with the analysis of variance ANOVA for a single-factor arrangement and the significance of the differences between groups was verified with Duncan's test. The non-parametric $\chi^{2}$ test was applied to breeding parameters. The calculations were performed with Statistica 10.0 software (StatSoft, Inc. Tulsa, OK, USA).

\section{Results}

\subsection{Results of breeding performance}

The breeding performance of the ewes is presented in Table 1 . In experiment 1 , it was found that fertility was higher in the groups of ewes receiving yeast supplements. The addition of Saccharomyces cerevisiae dried brewer's yeast (group II) generated an increase in the prolificacy of the ewes and was higher in comparison to the control group and the group administered Biolex (III) $(p \leq 0.01)$. A higher number of lambs born and reared in group II affected the level of breeding performance, which was higher by 35 and 30 percentage points ( $p \leq 0.01$ ), respectively, than groups I and III. The results of experiment 2 confirmed the impact of yeast on the prolificacy of the ewes recorded in experiment 1 . An increase of $31.66 \%$ in this parameter was recorded $(p \leq 0.01)$.

\subsection{Milk yield and chemical composition of milk}

The results of milk yield measurements are presented in Fig. 1. It was found that the average daily milk yield was higher in the ewes from the experimental groups. This tendency was observed throughout the lactation period and in its peak phase (day 28).

Together with an increase in milk yield, changes in the chemical composition of milk were recorded (Table 2). Milk from the experimental ewes had a higher content of dry matter. On day 28 of lactation, the differences in relation to group I were highly significant, whereas in the final stage a statistical advantage was only confirmed for group III $(p \leq 0.05)$.

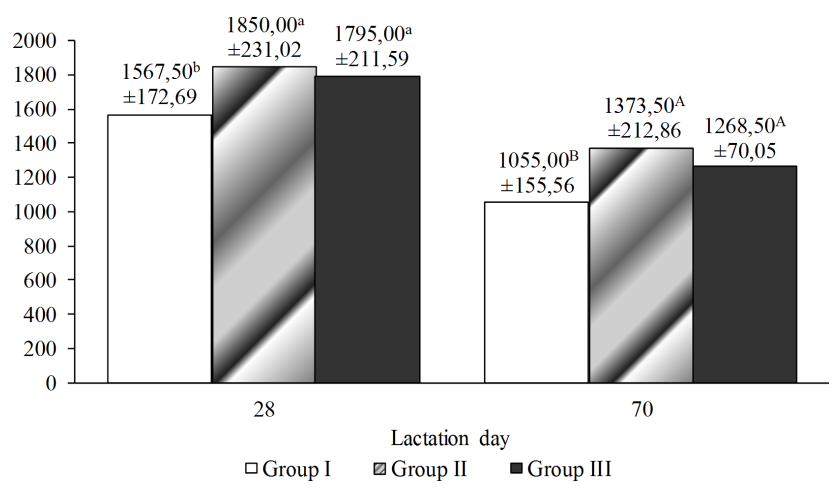

Figure 1. Daily dressing milk (in millilitres). ${ }^{\mathrm{a}, \mathrm{b}} p \leq 0.05$; A, B $p \leq 0.01$.

An increase in the content of dry matter was associated mainly with higher fat content. The concentration of fat was highest in milk from the ewes in the group III at both time points during lactation $(p \leq 0.01)$. On day 70 of lactation, fat content was still highest in group III $(p \leq 0.01)$ and in group II $(p \leq 0.05)$.

\subsection{Growth of lambs}

The data on the growth of lambs are presented in Table 3. No significant differences in body weight of lambs on day 2 and 28 were recorded between the groups. The lambs in group III that were fed Biolex Beta-S had a higher final body weight than both the control $(p \leq 0.05)$ and group II $(p \leq 0.01)$. Although the lambs in group II had lower body weight during the whole rearing period, the differences were not statistically significant in relation to the control group. The lambs in group III had higher daily weight gains throughout the rearing period compared to both groups I $(p \leq 0.05)$ and II $(p \leq 0.01)$. The differences were a consequence of higher daily weight gains between days 29 and 70 in group III in comparison with group I and II $(p \leq 0.01)$. Increased daily weight gains also caused a higher growth rate in the lambs from group III on days 29-70 and for the whole rearing pe$\operatorname{riod}(p \leq 0.05)$.

\section{Discussion}

In the literature, there are few papers on the impact of yeast on the functions of the reproductive tract in sheep. Kim et al. (2008), while administering live yeast to sows throughout the reproductive cycle, did not observe any impact from the supplement on litter size. Similarly, Bruno et al. (2009), investigating the effects of using live Saccharomyces cerevisiae cultures, did not find any impact on the ovulation cycle, efficacy of insemination or the number of abortions. Allbrahim et al. (2010) observed a higher pre-ovulatory surge of estradiol in cows administered live yeast, although this supplement did not impact the size of the ovulatory ovarian folli- 
Table 2. Chemical composition of milk.

\begin{tabular}{|c|c|c|c|c|c|c|c|}
\hline \multirow[t]{3}{*}{ Traits } & \multirow[t]{3}{*}{ Day of lactation } & \multicolumn{6}{|c|}{ Group } \\
\hline & & \multicolumn{2}{|c|}{ I } & \multicolumn{2}{|c|}{ II } & \multicolumn{2}{|c|}{ III } \\
\hline & & $\bar{x}$ & SD & $\bar{x}$ & SD & $\bar{x}$ & $\mathrm{SD}$ \\
\hline \multicolumn{8}{|c|}{ Chemical composition $(\%)$} \\
\hline \multirow{2}{*}{ Dry matter } & 28 & $15.45^{\mathrm{B}}$ & 0.74 & $16.28^{\mathrm{A}}$ & 0.80 & $16.81^{\mathrm{A}}$ & 0.86 \\
\hline & 70 & $17.58^{\mathrm{b}}$ & 1.18 & 18.23 & 0.91 & $18.56^{\mathrm{a}}$ & 0.74 \\
\hline \multirow{2}{*}{ Fat } & 28 & $5.12^{\mathrm{B}}$ & 0.64 & $5.60^{\mathrm{B}}$ & 0.75 & $6.46^{\mathrm{A}}$ & 0.92 \\
\hline & 70 & $6.34^{\mathrm{Bb}}$ & 0.77 & $7.27^{\mathrm{a}}$ & 0.62 & $7.65^{\mathrm{A}}$ & 0.70 \\
\hline \multirow{2}{*}{ Protein } & 28 & 4.65 & 0.49 & 4.99 & 0.38 & 4.88 & 0.47 \\
\hline & 70 & 5.32 & 0.37 & 5.56 & 0.55 & 5.83 & 0.30 \\
\hline \multirow{2}{*}{ Lactose } & 28 & 5.11 & 0.26 & 5.22 & 0.13 & 5.17 & 0.22 \\
\hline & 70 & 4.89 & 0.55 & 4.97 & 0.27 & 4.96 & 0.28 \\
\hline
\end{tabular}

a, b $p \leq 0.05 ;$ A, B $p \leq 0.01$

Table 3. Body weight, daily gain and growth rate of lambs.

\begin{tabular}{lllllll}
\hline Traits & \multicolumn{5}{c}{ Group } \\
\cline { 2 - 7 } & \multicolumn{2}{c}{ I } & \multicolumn{2}{c}{ II } & III \\
\cline { 2 - 7 } & $\bar{x}$ & SD & $\bar{x}$ & SD & $\bar{x}$ & SD \\
\hline Body weight $(\mathrm{kg})$ on day & & & & & & \\
\hline 2 & 5.03 & 0.65 & 4.81 & 0.76 & 4.99 & 0.89 \\
28 & 12.14 & 3.30 & 11.76 & 3.03 & 12.42 & 2.56 \\
70 & $19.47^{\mathrm{b}}$ & 5.41 & $18.59^{\mathrm{B}}$ & 4.98 & $21.42^{\mathrm{Aa}}$ & 5.69 \\
\hline Daily gain $(\mathrm{g})$ in the period & & & & & & \\
\hline 2-28 days & 273.43 & 114.99 & 267.36 & 106.88 & 285.78 & 89.30 \\
29-70 days & $174.39^{\mathrm{B}}$ & 82.15 & $162.76^{\mathrm{B}}$ & 76.96 & $214.37^{\mathrm{A}}$ & 92.84 \\
2-70 days & $212.26^{\mathrm{b}}$ & 76.12 & $202.75^{\mathrm{B}}$ & 68.68 & $241.68^{\mathrm{Aa}}$ & 80.76 \\
\hline Growth rate $(\%)$ in the period & & & & & & \\
\hline 2-28 days & 79.06 & 21.14 & 81.10 & 21.77 & 84.16 & 16.77 \\
29-70 days & $46.16^{\mathrm{b}}$ & 16.78 & $44.51^{\mathrm{b}}$ & 16.22 & $51.85^{\mathrm{a}}$ & 12.85 \\
2-70 days & $114.56^{\mathrm{b}}$ & 16.58 & $115.04^{\mathrm{b}}$ & 17.09 & $122.13^{\mathrm{a}}$ & 15.25 \\
\hline a, b $p \leq 0.05 ;$ A, B $p \leq 0.01$ & & & & & & \\
& & & & & & \\
\hline
\end{tabular}

cles. The results of this study indicate that the stimulation of the reproductive tract in ewes was induced by Saccharomyces cerevisiae dried brewer's yeast, resulting in an increase in the number of ovulating ova and, consequently, in higher prolificacy. The results show that the yeast products administered to the ewes stimulated their milking potential, which confirms the findings reported by other authors. Milewski and Sobiech (2009) used an addition of Saccharomyces cerevisiae dried brewer's yeast in sheep nutrition and recorded an increase in milk yield of $18.8 \%$ in the peak phase and $15.53 \%$ in the final phase of lactation. Ząbek et al. (2014) administered the same preparation to ewe mothers in late pregnancy and lactation or during lactation and observed an increase in milk yield of 16.54 and $19.84 \%$ on day 28 and by 11.09 and $19.96 \%$ on day 70 . In dairy cow nutrition, this supplement generated an increase in milk yield of $12.47 \%$ (Dobicki et al., 2006, 2007). Ząbek et al. (2013) demonstrated the beneficial impact of $\beta$-1,3/1,6-D-glucan on milk yield in sheep. Biolex Beta-S yeast supplement generated an increase in milk yield of $13.54 \%$ on day 28 and $14.04 \%$ on day 70 of lactation. The addition of the supplements induced changes in milk composition. A higher content of fat in milk from the 
ewes administered Biolex Beta-S may result from the impact of $\beta$-glucan on lipid metabolism (Cui and Wang, 2009). The authors relate it to increased health status of ewes induced by the administered immunostimulator. The results of the study conducted by Dobicki et al. (2006) indicate that an increase in milk yield induced by yeast supplements results from their impact on ruminal microbiota and, consequently, more efficient degradation of fiber obtained from the diet. Normalization of the energy balance and improved utilization of nutrients stimulate milk production.

The lambs receiving Biolex were characterized by a higher body weight and growth rate. The obtained results confirm the findings of studies by Milewski (2009), Milewski et al. (2007, 2010) and Ząbek et al. (2013), who recorded an increase in daily weight gains and, consequently, in body weight in lambs administered Saccharomyces cerevisiae supplements. Similar results were reported by Tripathi and Karim (2010), who administered live yeasts to lambs. Ząbek et al. (2014) concluded that supplementation of the diets for mothers in late pregnancy and lactation or during lactation with a yeast product favourably impacted the offspring growth rate, which was the result of higher milk yield in mothers. Lower weight gains in lambs fed Inter Yeast $S$ dried brewer's yeasts in comparison with the other groups, reported in the study conducted by the authors, may be explained by the substantially higher prolificacy of mothers. As a result, their lambs had lower growth rates despite high milk yield in the mothers. However, it should be emphasized that the final volume of livestock production per mother was higher by $20.21 \%$ in this group compared to the control group, while this index in the group that was administered $\beta$-glucan was higher by $14.07 \%$.

Edited by: S. Maak

Reviewed by: two anonymous referees

\section{References}

Allbrahim, R. M., Crowe, M. A., Duffy, P., O’Grady, L., Beltman, M. E., and Mulligan, F. J.: The effect of body condition at calving and supplementation with Saccharomyces cerevisiae on energy status and some reproductive parameters in early lactation of dairy cows, Anim. Reprod. Sci., 121, 63-71, 2010.

Bruno, R. G. S., Rutigliano, H. M., Cerri, R. L., Robinson, P. H., and Santos, J. E. P.: Effect of feeding Saccharomyces Cerevisiae on the performance of dairy cows during summer heat stress, Anim. Feed. Sci. Technol., 150, 175-186, 2009.

Cui, S. W. and Wang, Q.: Cell wall polysaccharides in cereals: chemical structures and functional properties, Struct. Chem., 20, 291-297, 2009.

Dobicki, A., Preś, J., Łuczak, W., and Szyrner, A.: Influence of dried brewery's yeast on body weight gains, physiological and biochemical indicators of blood and development of the rumen micro-organisms in calves, Med. Weter., 61, 946-949, 2005 (in Polish).
Dobicki, A., Preś, J., Zachwieja, A., and Kwaśnicki, R.: Saccharomyces cerevisiae preparations in the feeding of cows and their effect on milk yield and composition as well as rumen microorganisms, EJPAU, 9, 48, 2006.

Dobicki, A., Preś, J., Zachwieja, A., Mordak, R., and Jakus, W.: Influence of yeast preparations on chosen biochemical blood parameters and the composition of cow milk, Med. Weter., 63, 951954, 2007 (in Polish).

Erasmus, L. J., Robinson, P. H., Ahmadi, A., Hinders, R., and Garrett, J. E.: Influence of prepartum and postpartum supplementation of a yeast culture and monensin, or both, on ruminal fermentation and performance of multiparous dairy cows, Anim. Feed. Sci. Technol., 122, 219-239, 2005.

Kim, S. W., Brandherm, M., Freeland, M., Newton, B., Cook, D., and Yoon, I.: Effects of Yeast Culture Supplementation to Gestation and Lactation Diets on Growth of Nursing Piglets, Asian.Aust. J. Anim. Sci., 21, 1011-1014, 2008.

Linge, P.: The use of probiotics and yeast derivatives in India, World Poultry, 21, 12-15, 2005.

Milewski, S.: Effect of yeast preparations Saccharomyces cerevisiae on meat performance traits and blood hematological indices in sucking lambs, Med. Weter., 65, 51-54, 2009 (in Polish).

Milewski, S. and Sobiech, P.: Effect of dietary supplementation with Saccharomyces cerevisiae dried yeast on milk field, blood biochemical and haematological indices in ewes, Bull. Vet. Inst. Pulawy., 53, 753-758, 2009.

Milewski, S., Wójcik, R., Małaczewska, J., Trapkowska, S., and Siwicki, A. K.: Effect of $\beta-1.3 / 1.6-D$-glucan on meat performance and non-specific humoral defense mechanisms in lambs, Med. Weter., 63, 360-363, 2007 (in Polish).

Milewski, S., Sobiech, P., Bednarek, D., Wójcik, R., Małaczewska, J., Zaleska, B., and Siwicki, A. K.: Effect of oligosaccharides supplementation on the meat performance traits and selected indicators of humoral immunity in lambs, Bull. Vet. Inst. Pulawy., 54, 175-179, 2010.

Niżnikowski, R. and Rant, W.: Impact assessment fathers on the level of selected milk traits of the east dairy ewes and type corriedale, Zeszyty Naukowe Przeglądu Hodowlanego, 34, 123 131, 1997 (in Polish).

Tripathi, M. K. and Karim, S. A.: Effect of individual and mixed live yeast culture feeding on growth performance, nutrient utilization and microbial crude protein synthesis in lambs, Anim. Feed. Sci. Technol., 155, 163-171, 2010.

Wójcik, R., Małaczewska, J., Trapkowska, S., and Siwicki, A. K.: Influence of $\beta-1,3 / 1,6-\mathrm{D}$-glucan on non-specific cellular defence mechanisms in lambs, Med. Weter., 63, 84-86, 2007 (in Polish).

Ząbek, K., Milewski, S., Wójcik, R., and Siwicki, A. K.: Effect of $\beta-1,3 / 1,6-\mathrm{D}$-glucan in diet on productivity and humoral and cellular defense mechanisms in sheep, Acta Vet., Brno, 82, 141146, 2013.

Ząbek, K., Milewski, S., Wójcik, R., and Siwicki, A. K.: The effects of supplementing diets fed to pregnant and lactating ewes with Saccharomyces cerevisiae dried yeast, Turk. J. Vet. Anim. Sci., 38, 200-206, 2014. 